\title{
A escrita de estudantes na universidade: uma análise das dimensões dos indivíduos
}

Students' writing in university: an analysis of the dimensions of individuals

Elizabeth Maria da Silva*

Universidade Federal de Campina Grande

Resumo A partir de uma problematização sobre o conflito que se estabelece entre as expectativas de ensino e as de aprendizagem da escrita acadêmica, sugerimos que os "suportes amigáveis" são uma das alternativas a que os estudantes recorrem a fim de tentar lidar com esse conflito. Esses suportes podem ser úteis também para que os alunos reconheçam, paulatinamente, a existência de relações de poder e autoridade perpassando a produção textual acadêmica, bem como a necessidade de incorporar o papel social e a identidade exigidos pela academia.

PALAVRAS-ChAVE: Escrita acadêmica; "Suportes amigáveis"; Papel social; Identidade.

Abstract From a questioning about the conflict established between academic writing learning and academic writing educational expectations, we suggest that the "friendly supports" are one of the alternatives which students use to try to deal with this conflict. These supports can also be useful for students to recognize, gradually, the existence of authority and power relations permeating academic text production, as well as the need to incorporate the social role and identity required by the academy.

KEYWORDS: Academic writing; "Friendly supports"; Social role; Identity. 


\section{Introdução}

No âmbito das discussões que vêm sendo realizadas sobre os vários desafios da educação superior brasileira, gostaríamos de focalizar, no presente ensaio, uma variável extremamente importante: a escrita acadêmica, considerada uma das principais formas avaliativas adotadas pelos professores para analisar o desempenho dos estudantes. É por meio da produção de diferentes gêneros textuais, a exemplo de resumos, resenhas, estudos dirigidos, fichamentos, relatórios, artigos e projetos, que os docentes observam se seus alunos estão atendendo ou não às suas expectativas. No entanto, tendo em vista que esses textos circulam e são produzidos na universidade, é esperado que os graduandos não tenham familiaridade com os mesmos e, consequentemente, não saibam como produzi-los (MARINHO, 2010; FIAD, 2011, 2013; FISCHER, 2011, 2012). Sendo assim, urge-nos indagar: os professores ensinam como produzir esses gêneros? Explicitam que critérios adotam para corrigi-los? A nosso ver, com raras exceções (LEA; STREET, 2006; STREET, 2009), a resposta para ambas perguntas é "não".

A solicitação e a avaliação dos textos acadêmicos são fundamentadas, em geral, pela crença de que os estudantes de graduação (e também os de pós-graduação) já conhecem as convenções da escrita acadêmica, visto já terem passado por vários anos de escolarização. Subjacente a essa crença está uma abordagem denominada por Lea; Street (1998) de estudo de habilidades, na qual a escrita é considerada como um conjunto de habilidades linguísticas que, uma vez aprendido, pode ser transferido para quaisquer situações. Ainda segundo essa crença, se o aluno aprendeu a escrever na educação básica, não terá dificuldades de escrever na educação superior, pois, diante das exigências da escrita acadêmica, deverá apenas recorrer às suas experiências anteriores. No entanto, a escrita é muito mais que habilidades, é também, e sobretudo, uma prática social variável, dinâmica, heterogênea, perpassada por relações de poder, de autoridade e de identidade, conforme explorado no modelo dos letramentos acadêmicos proposto por Lea; Street (1998).

Esses aspectos relativos à escrita não são explicitados aos estudantes, quando são incumbidos de produzir textos acadêmicos. Na verdade, conforme argumenta Lillis (1999), as convenções que regulam a escrita não são transparentes nem para quem faz parte da comunidade acadêmica, nem para quem pretende nela inserir-se. Em decorrência disso, o processo avaliativo é marcado por uma "prática institucional do mistério", afirma a autora (op. cit.). O "mistério" que caracteriza a avaliação da escrita acadêmica pode ser justificado segundo vários aspectos, mas entendemos que dois são os mais recorrentes: de um lado, os docentes não explicitam para os alunos as convenções da escrita, seja pelo motivo já exposto (partem da premissa de que eles já devem conhecê-las), seja por que desconhecem (ou conhecem pouco) tais convenções; de outro, os estudantes não perguntam aos professores como devem escrever na academia.

Nesse contexto da "prática institucional do mistério" em relação ao que conta como escrita nos processos avaliativos, temos o que Street (2009) denominou de "dimensões escondidas" da natureza contextualizada da escrita acadêmica. Segundo o autor (op. cit.), há dimensões no processo de produção textual que permanecem, 
muitas vezes, ocultas, dada a não explicitação dos critérios utilizados por professores, orientadores de pesquisas, avaliadores de trabalhos submetidos a congressos e revisores de periódicos. Tais dimensões, argumenta o autor (op. cit.), não dizem respeito apenas à estrutura do texto, mas também ao seu enquadramento (Qual o gênero a ser produzido? Para quem? Com qual finalidade?), à sua contribuição (Que contribuições a pesquisa fornecerá para o conhecimento, para a área de estudo e para investigações futuras?), à voz do autor, ao ponto de vista e às marcas linguísticas.

Partindo do pressuposto de que essas dimensões da escrita não são explicitadas para os estudantes e estes, na maioria das vezes, não perguntam para os professores como escrever os textos que lhes são solicitados, surge-nos o questionamento: o que os graduandos fazem para atender às exigências do professor? Evidentemente que há várias respostas, de natureza bastante distinta, para essa pergunta, mas gostaríamos de respondê-la, no próximo item, chamando a atenção para um fator que parece-nos relevante no processo de produção de textos acadêmicos, a saber: os "suportes amigáveis" e suas implicações para a incorporação do papel social e da identidade exigidos na universidade.

\section{Descobrindo os "mistérios" da escrita acadêmica: os "supor- tes amigáveis" e suas implicações}

Entendemos que, ao se deparar com um contexto marcado pela "prática institucional do mistério" e por "dimensões escondidas" no tocante ao que conta como escrita acadêmica, o estudante recorre, na maioria das vezes, ao que estamos chamando de "suportes amigáveis", a fim de atender às exigências do seu professor. Estamos sugerindo essa perspectiva teórica como uma das possibilidades para responder à pergunta supramencionada, com base no conceito de uma das dimensões do indivíduo apresentada por Martuccelli (2007) ${ }^{1}$, qual seja, o "suporte".

De acordo com o autor (op.cit.), os suportes se configuram como forças sociais que auxiliam o indivíduo ${ }^{2}$ a lidar com as diversas situações das quais participa diariamente: suportes culturais, afetivos, religiosos e materiais. Reconhecê-los como elementos que influenciam a vida das pessoas implica desconstruir aquela ideia de que existe uma figura ideal de indivíduo, segundo a qual ele é considerado dono de si mesmo, autônomo, independente, detentor de auto-controle pessoal e de sua expressão interior (MARTUCCELLI, op.cit., p. 38). Nesse sentido, para o autor, o indivíduo não consegue atingir as suas metas sozinho, visto que a autonomia não nasce dentro dele; ele pode até ter força de vontade, mas são as forças externas que o impulsionam, ou seja, são os suportes que lhe permitem alcançar a sua autonomia.

Esse conceito de suporte pode ser útil para pensarmos um pouco sobre a escrita acadêmica. Ao se depararem, na universidade, com propostas de produção textual diferentes das que estavam acostumados a fazer, os estudantes não conseguirão, sozinhos e de modo autônomo, atender às convenções requisitadas nessas propostas, de modo que sentirão, consciente ou inconscientemente, a necessidade de recorrer a suportes. Mas a que tipo de suporte? Será que as experiências de escrita advindas de contextos religiosos, familiares, pessoais, digitais se configuram como suportes para o 
desenvolvimento da escrita acadêmica? A nosso ver, esses contextos podem até exercer uma certa influência, porém, não decisiva, uma vez que concebemos a escrita como uma prática social historicamente situada, que assume significados específicos conforme os propósitos das instituições/grupos sociais em que aparece, bem como das relações de poder e de identidade que a subjaz (LEA; STREET, 1998).

Considerar a escrita como uma prática social implica reconhecer que, justamente por ser social e situada, demandará dos estudantes, foco dessa reflexão, ações específicas no tocante à produção de textos acadêmicos. Como essas ações não são explicitadas pelos professores, os alunos precisarão recorrer aos "suportes amigáveis", caso queiram obter, ou melhor, tentar obter êxito. Esses "suportes amigáveis" englobam, de um lado, estudantes que já passaram pela experiência com a escrita acadêmica; de outro, colegas que estão vivenciando essa experiência. Esse tipo de suporte, embora tenha como ponto de partida a definição de suporte apresentada por Martuccelli (op. cit.), se difere da tipologia apresentada por ele, na medida em que, enquanto os expostos por esse autor são mais gerais e externos ao contexto imediato em que o indivíduo se encontra, o que estamos sugerindo é mais específico e relacionado à situação em que ele está inserido.

No caso do primeiro tipo de "suporte amigável", temos que, diante de uma determinada proposta de produção de texto acadêmico desconhecida do graduando, este pede ajuda a outros graduandos que já o produziram, em um outro momento, para o mesmo professor. A busca por esse suporte se justifica pelo fato de que aqueles que já elaboraram os textos possivelmente saberão dizer o que os docentes esperam das produções escritas, que critérios são adotados no processo avaliativo, os quais não devem ter sido explicitados pelo professor, mas inferidos pelos discentes. Nessa troca de conhecimentos, os estudantes podem descobrir algumas daquelas dimensões escondidas expostas por Street (2009). Quando avalia um texto acadêmico, o docente adota critérios de que natureza? $\mathrm{O}$ domínio da variedade padrão do português? $\mathrm{O}$ domínio das normas da Associação Brasileira de Normas Técnicas (ABNT)? O domínio dos fatores de textualidade, como coesão e coerência? $\mathrm{O}$ domínio da estrutura do gênero textual? As questões ideológicas que perpassam a produção desses textos? Todos esses aspectos? Somente alguns?

Ao se configurarem como "suportes amigáveis" de estudantes que não sabem como produzir textos acadêmicos, os alunos "experientes" (talvez, nem sejam tão experientes assim) podem orientar aqueles no tocante ao que conta como escrita para determinado professor. Essa informação é relevante na medida em que a escrita acadêmica tende a variar conforme cada professor (LEA; STREET, 2006; ZAVALA, 2009), logo, conhecer o docente, no sentido de estar ciente em relação ao que ele valoriza e ao que ele desconsidera na escrita dos textos, pode contribuir para que o aluno obtenha um desempenho satisfatório nas atividades de escrita.

Já no segundo tipo de "suporte amigável", temos que, diante da exigência de produzir um determinado gênero acadêmico que não conhecem, os estudantes de uma mesma turma se unem a fim de tentar descobrir como elaborá-lo, como se estivessem participando de um “jogo de adivinhação" (IVANIC, 1998), cujo objetivo é adivinhar 
o que conta como escrita acadêmica para os professores. Conforme relatos informais de alguns graduandos, há algumas estratégias às quais eles recorrem para desvendar o "mistério" da escrita acadêmica, a exemplo de se reunir, seja presencial, seja virtualmente (pelo msn, facebook, grupo de e-mail) a fim de saber como o colega está escrevendo o texto que foi solicitado, relatar as dificuldades que estão sentindo, expor os insights que estão tendo, enfim, socializar experiências e aprender com elas. Nesse caso, cada aluno pode ser um "suporte amigável" para o colega, pode contribuir para o processo de aprender a escrever do outro, pode, portanto, ajudá-lo a desvendar as dimensões escondidas da escrita acadêmica.

Ao se ancorarem nesses "suportes amigáveis", que não se excluem, podendo, inclusive, ser utilizados simultaneamente, os estudantes irão perceber, paulatinamente, a existência de relações de poder e autoridade perpassando a produção textual acadêmica. Em decorrência dessa percepção, verificarão, ainda que a longo prazo, que, para serem integrados, de fato, à comunidade universitária e reconhecidos como membros legítimos dessa comunidade, deverão assumir o papel social e a identidade exigidos nessa esfera.

De acordo com Martuccelli (2007), o papel social é o que faz o vínculo entre estruturas sociais e atores, relacionando modelos de conduta aos diversos status ou a posições sociais. No caso dos graduandos, ao chegarem à universidade, eles devem assumir o papel social de estudante do ensino superior que, diferentemente do ensino médio em que escreviam textos mais genéricos e ligados a diversas esferas sociais (artigo de opinião, editorial, cartas, notícia, depoimento, relato, etc.), produzirão textos mais complexos e específicos desse nível de ensino (artigo acadêmico, projeto de pesquisa, relatório, monografia, etc.).

Ainda conforme o autor (op. cit., p. 119), quando o papel social esperado por determinada instituição é assumido, as interações entre os indivíduos nessa instituição são estáveis e previsíveis, já que o papel evidencia o comportamento esperado em função do lugar que o indivíduo ocupa em um sistema social dado. Assim, quando o recém-ingresso desempenha o papel social de estudante do curso superior, espera-se que, dentre outras atribuições, ele escreva os textos que the são exigidos, demonstrando apropriação do discurso acadêmico que os subjaz. Se pensarmos em um ensaio, por exemplo, é esperado do produtor, dentre outras ações, articular conceitos apresentados por diferentes autores, não plagiar, assumir uma posição teórica, explicitar a sua voz enquanto autor. Além de assumir esse papel social, os alunos deverão incorporar também uma identidade acadêmica, a fim de atender às exigências da universidade e, assim, ser reconhecidos como membros da academia por parte daqueles que têm o poder de fazê-lo, os agentes de letramento (professores, orientadores, arguidores).

Assumir uma identidade discursiva que não é a deles, que não reflete a imagem que eles têm de si, é um desafio para os estudantes: "eu quero dizer muitas coisas neste ensaio, mas eles não querem ouvir", desabafa um dos participantes da pesquisa desenvolvida por Lillis (2003, p. 203), que analisou as perspectivas de alunos quanto aos feedbacks dados pelos seus professores nos textos que produziram. Paula está satisfeita por ter aprendido formas acadêmicas, mas não se sente ela mesma quando escreve. 
Ela escreve o texto com o conteúdo que é esperado institucionalmente, mas desabafa que vive um conflito: "quero falar, me comportar e ser a mesma que antes e pensar da maneira que eles pensam" [familiares] - constatações de Zavala (2009, p. 355), quando analisou uma série de entrevistas feitas com a estudante universitária Paula sobre a sua escrita acadêmica.

Essas falas dos estudantes ratificam o que Martuccelli (op.cit.) constata em relação à identidade: os indivíduos têm muitas identidades e, na maioria das vezes, sofrem grandes conflitos identitários. No caso dos exemplos expostos, temos, de um lado, a identidade familiar dos estudantes que eles gostariam de assumir na realização de suas atividades de escrita acadêmica; de outro, a identidade acadêmica exigida pelos professores-avaliadores das tarefas de escrita. Assim, ainda que o estudante chegue à universidade com a identidade familiar e com outras identidades, lá (na universidade), ele deverá se apropriar da identidade acadêmica.

O conflito identitário evidencia, portanto, os dois processos que estão totalmente imbricados na dimensão identitária dos indivíduos, quais sejam: (1) Aquilo que garante a permanência no tempo de um indivíduo, apesar de todas as mudanças que sofre, é sempre o mesmo indivíduo - aspectos pessoais - e (2) Série de perfis sociais e culturais próprios dos indivíduos, nas sociedades modernas - aspectos coletivos (MARTUCCELLI, 2007, p. 289). Ou seja, a identidade não diz respeito apenas à singularidade pura, homogênea e intocável do indivíduo, nem apenas à materialização de aspectos sociais, culturais e históricos de determinado contexto. $\mathrm{Na}$ verdade, a identidade resulta da articulação entre os dois: uma história pessoal do indivíduo e uma tradição social e cultural.

Reconhecer esses dois processos que constituem a dimensão identitária significa reconhecer que nenhum indivíduo possui uma única identidade, dispõe, pelo contrário, de posições múltiplas, atravessadas por discursos e práticas que podem ser até contraditórias, como destaca Martuccelli (op. cit., p. 322). Assim sendo, a identidade não é algo fixo, como pensam os defensores da visão holística da sociedade, mas flexível e em constante modificação, a depender das circunstâncias. O indivíduo pode criar uma identidade apenas para resolver um problema. Após resolvê-lo, pode abandoná-la. Isso acontece frequentemente com os estudantes, quando são incumbidos de realizar determinada tarefa de escrita. Assumem a identidade que é esperada pelo professor, para que possam obter um bom desempenho na atividade, ainda que não acreditem naquilo que estão escrevendo. Feita a atividade, deixam essa identidade cria$\mathrm{da}$ (principalmente quando não se identificam com ela) e incorporam outra(s).

\section{Considerações finais}

Neste breve ensaio, buscamos, a partir de uma problematização sobre a "prática institucional do mistério", que parece caracterizar as exigências de atividades de escrita acadêmica, sugerir uma possibilidade para responder à pergunta norteadora da nossa reflexão: $\mathrm{O}$ que os graduandos fazem para atender às exigências do professor? A possibilidade que apresentamos para respondê-la foi a de que os estudantes recorrem a "suportes amigáveis", constituídos seja por estudantes que já passaram pela experiência 
com a escrita acadêmica, seja por colegas que estão vivenciando a experiência no momento em que ocorre. Esses suportes, a nosso ver, podem implicar, ainda que a longo prazo, o reconhecimento, por parte dos discentes, de que há relações de poder e autoridade perpassando a produção textual acadêmica, as quais exigem a incorporação de um papel social e de uma identidade específicos, exigidos na comunidade acadêmica.

Entendemos que esses "suportes amigáveis" são uma variável que deve ser considerada quando se trata de discutir a escrita acadêmica, na medida em que revela estratégias/artifícios, em geral, desconhecidos dos professores, que os estudantes utilizam para atender às exigências de determinadas atividades de escrita. Revelam que, apesar da "prática institucional do mistério" e das "dimensões escondidas", os alunos tentam (estão tentando) atender às expectativas dos docentes. Pode ser que não consigam descobri-las ou que não as atendam como o esperado, mas eles estão procurando fazer a parte deles. É fato que há muitos outros estudantes que não estão interessados nisso, que escrevem os textos de qualquer forma, que "enrolam" o professor, que estão interessados apenas em ser aprovados na disciplina. Sempre haverá alunos com esse perfil, independentemente do nível em que se encontram e da instituição onde estudam. No entanto, queremos chamar a atenção para o fato de que os "suportes amigáveis" podem auxiliar os alunos ao longo do curso. É na conversa com outros estudantes que eles se sentem mais à vontade para relatar tanto as suas dificuldades, medos e dúvidas quanto as suas aquisições, avanços e potencialidades.

Reconhecemos que essa nossa reflexão é bastante inicial, fundamentada apenas em relatos informais dados por diferentes estudantes. Entretanto, serve como ponto de partida para fazermos uma investigação empírica mais sistematizada a partir da realização de entrevistas com alunos, não só os de graduação, mas também os de pós-graduação. É possível, inclusive, que outros "suportes amigáveis" sejam referidos por esses sujeitos, a exemplo da busca em sites da internet, como o google, de informações sobre como se escreve o texto acadêmico solicitado por um determinado professor. Ademais, precisamos investigar também os reflexos da apropriação de um novo papel social e de uma nova identidade nas produções textuais desses discentes.

\section{Referências}

FIAD, R. S. Reescrita, dialogismo e etnografia. Linguagem em (Dis)curso, Tubarão, v. 13, n. 3, p. 463-480, set. /dez. 2013.

. A escrita na universidade. Revista da ABRALIN, v. Eletrônico, n. Especial, p. 357-369. $2^{\text {a }}$ parte, 2011. Disponível em: <http://www.abralin.org/revista/RVE2/14v.pdf >. Acesso em: 10 fev. 2014.

FISCHER, A. "Dimensões escondidas" e "instrução explícita” em práticas de letramento acadêmico: o caso do relatório de projeto em um curso de Engenharia de Portugal. Linguagem \& Ensino, Pelotas, v. 15, n. 2, p. 487-504, jul./dez. 2012.

Práticas de letramento acadêmico em um curso de Engenharia Têxtil: o caso dos relatórios e suas dimensões escondidas. Scripta, Belo Horizonte, v. 15, n. 28, p. 37-58, $1^{\circ}$ sem., 2011.

IVANIC, R. Writing and identity: the discoursal construction of identity in academic writing. Filadelfia, Jonh Benjamins, 1998. 
LEA, M. R; STREET, B. V. The "Academic literacies" model: theory and applications. Theory into practice. Fall 2006, v. 45, n. 4, p. 368-377.

Student writing in higher education: an academic literacies approach. Studies in Higher Education, v. 23, n. 2, p. 157-172, 1998.

LILLIS, T. Student writing as 'Academic literacies': drawing on Bakhtin to move from critique to design. Language and Education 17, 3: 192-207, 2003.

. Whose 'common sense'? Essayist literacy and the institutional practice of mystery.In: JONES, C.; TURNER, J.; STREET, B. (Orgs.). Students writing in the university: cultural andepistemological issues. Amsterdam, John Benjamins, 1999, p. 127-140.

MARINHO, M. A escrita nas práticas de letramento acadêmico. Revista Brasileira de Linguística Aplicada, Belo Horizonte, v. 10, n. 2, p. 363-386, 2010.

MARTUCCELLI, D. Gramáticas del individuo. Buenos Aires: Losada, 2007.

STREET, B. “Hidden' features of academic paper writing” Working papers. Educational Linguistics, UPenn, v. 24, n. 1, p. 1-1, 2009. Disponível em: <http://www.gse.upenn.edu/sites/gse. upenn.edu.wpel/files/archives/v24/Street.pdf >. Acesso em: 10 fev. 2014.

ZAVALA, V. "Quién está dicendo eso?” Literacidad acadêmica, identidade y poder em laeducacion superior. In. KALMAN; STREET (Coord.). Lectura, escritura e matemáticas. México: Siglo XXI. p. 348-363, 2009.

\section{Notas}

${ }^{1}$ Em seu livro Gramáticas Del individuo, Martuccelli apresenta, além dessa dimensão, mais quatro dimensões: respeito, subjetividade, papel social e identidade. Essas duas últimas também serão focalizadas no presente ensaio.

${ }^{2}$ Entendido nos termos de Martuccelli (2007, p. 10) como não apenas um ator social, mas também um ator empírico; um sujeito que se apóia em uma representação histórica e normativa participante.

* Professora da Universidade Federal de Campina Grande, Campina Grande, Paraíba, Brasil.

\section{Correspondência}

Elizabeth Maria da Silva - Universidade Federal de Campina Grande, Unidade Acadêmica de Letras. Aprígio Veloso, 882, Bodocongó, CEP: 58109-000 - Campina Grande, Paraíba - Brasil.

E-mail: professoraelizabethsilva@gmail.com

Recebido em 27 de julho de 2014

Aprovado em 23 de março de 2015 